\title{
Exports, growth and financial stability in the euro area and beyond
}

\author{
Ansgar Belke ${ }^{1,2} \cdot$ Keith Pilbeam $^{3}$
}

Published online: 8 June 2016

(C) Springer-Verlag Berlin Heidelberg 2016

From June 12 to 15, 2014 the European Economics and Finance Society (EEFS) hosted its Thirteenth Annual Conference in Thessaloniki in collaboration with the journal "International Economics and Economic Policy". The conference addressed the broad theme of exports, growth and financial stability issues in the euro area and beyond. The focus was strongly on deriving policy conclusions to lessen the probability of further crises and to identify issues and questions for further research.

A peer-reviewed selection of the papers presented at the conference is presented in this issue. These contributions can be grouped around two main topics. Five papers fall into the category of micro and macroeconomic adjustment in the euro area programme countries. Four of them deal with the most significant country case, namely, Greece and the puzzle of its missing export growth.

Our compilation starts with the paper by Cinzia Alcidi, Ansgar Belke, Alessandro Giovannini and Daniel Gros which comes up with an overall assessment of the macroeconomic adjustment programmes in the euro area. Since the start of Economic and Monetary Union (EMU), the euro area, and more broadly the global economy, experienced an unprecedented credit boom. The expansion of credit was particularly strong in Greece, Ireland, Portugal and Cyprus and all of them subsequently needed official financial support. In each of the four programmes, financial assistance has been provided and promised against the commitment of each country to fulfil certain economic policy conditions contained in the macroeconomic adjustment programme.

Ansgar Belke

ansgar.belke@uni-due.de

1 Ad personam Jean Monnet Chair und Fakultät für Wirtschaftswissenschaften, Lehrstuhl für Volkswirtschaftslehre, insbes, Makroökonomik und Direktor des Instituts für Betriebswirtschaft und Volkswirtschaft (IBES), Universität Duisburg-Essen, Universitätsstr. 12, D-45117 Essen, Germany

2 Forschungsinstitut zur Zukunft der Arbeit GmbH (IZA), Schaumburg-Lippe-Strasse 5-9, 53113 Bonn, Germany

3 City University London, Northampton Square, EC1V 0HB London, UK 
In general, a macroeconomic adjustment is a process driven by policies but also by changes in private spending behaviour (consumption, imports and investment) and improvements in competitiveness that countries are required to undertake after a large shock. In the case of the four countries concerned the shock emerged as a consequence of an excessive accumulation of imbalances in different parts of the economy: in the public sector in Greece, in the housing and banking sectors in Ireland, external imbalances in Portugal and in the banking sector in Cyprus. For the purpose of assessing the macroeconomic adjustment programmes, the authors look at the feasibility of the fiscal adjustment comparing the macroeconomic conditions in the four countries and emphasising the role of the fiscal multipliers in the process. They also assess the fall in output in a comparative framework, stressing the role played by the different components of demand either in amplifying the effects of the fiscal consolidation or in offsetting it. Moreover, they consider the formulation of the programmes as well as their implementation with most attention devoted to reforms aiming at improving competitiveness, growth and employment in the framework of a cross-country approach.

The special issue continues with four papers on the case of Greece. The paper by George Agiomirgianakis, George Sfakianakis and Fotini Voulgaris deals with the determinants of economic growth and investigates whether improvements in competitiveness and investment represent a solution for Greece. They assess the role of debt as an additional determinant of growth complementing the relevant empirical growth literature and using insights gained during the recent economic crisis. Their focus is the case of Greece, the country most severely affected by the crisis and ultimately forced to resort to tripartite external assistance. More specifically, they explore whether the pillars of the Troika Adjustment Programme for Greece are the key to overcome the current deadlock in the Greek economy. They conclude that the required fiscal consolidation resulted in deep recession which actually jeopardized the sustainability of the improvement in general government accounts. The Troika Programme for Greece featured specific structural reforms as a prerequisite to improve the business environment and enhance the outward orientation of the Greek economy, thus identifying investment (domestic and foreign) and international competiveness as the new growth drivers of the Greek economy. Using panel data for EU countries, the authors investigate the validity of the proposed economic policy mix, placing special emphasis on the role that indebtedness (both private and public) has played in the past and could play in the future. As public debt is ruled out for financing investment but credit expansion to the private sector through increased liquidity is a sine qua non condition for the recovery of investment. The innovation of this study is that it takes the stock of both structural reforms and indebtedness and estimates their relevant impact on growth.

In their contribution, Nikolaos Kanellopoulos and Georgia Skintzi strive to identify export opportunities for Greece. For this purpose, they present a decision support model (DSM) and implement it to identify probable and realistic export opportunities for Greece. The aim of the model is to select those combinations of products and countries of destination (markets) that are attractive based on widely recognized criteria (such as country risk indicators, macroeconomic data, market shares, accessibility of the destination country and degree of market concentration etc.). The DSM consists of a filtering process during which the less attractive export opportunities are successively eliminated in order to focus on those markets that have the desired characteristics. 
International trade data at the HS six-digit level up to 2011 are used. The results indicate that there exists significant export opportunities for Greece. Export opportunities are listed and categorized according to criteria such as the market characteristics of the destination country and Greece's market share.

In the next paper, Theodore Panagiotidis and Panagiotis Printzis assess the macroeconomic determinants of the housing market in Greece and also examine the role of the housing market in the Greek economy. For this purpose, the authors review the literature and assess the interdependence between the Greek housing price index and its macroeconomic determinants within a VECM framework. An equilibrium relationship exists and in the long run the retail sector and mortgage loans emerge as the most important variables for housing. Their dynamic analysis shows that the mortgage loans followed by retail trade are the variables with the most explanatory power for the variation of the house price index.

In a final paper on Greece Ersi Athanassiou, Nikolaos Kanellopoulos, Roxani Karagiannis, Ioannis Katselidis and Agapi Kotsi measure the intensity of the reforms in professions and economic activities in Greece via a composite regulation index. The institutional framework regulating professions and economic activities of the service sector in Greece has recently been extensively liberalised to promote competition, conform to European Union regulations and fulfill commitments under the Memoranda of Economic and Financial Policies. The authors aim to capture quantitatively this major structural reform, by measuring for the first time the degree of regulation in 90 professions / activities affected by the relevant reform laws. The degree of regulation is measured both for the regime before and after the laws and the methodology employed is that of composite regulation indices. The index values obtained are used for evaluating the extent of the reforms and estimating correlations and regressions. The results of the analysis point to the existence of significant barriers to competition before the reforms and extensive liberalisation of the regulatory framework after the adoption of the relevant laws. Moreover, the results suggest that professions/activities characterised by more stringent restrictions before the reforms tend to be characterised by a comparatively higher intensity of regulations after the reforms.

As a kind of more general benchmark paper, Joscha Beckmann and Rainer Schweickert analyse the issue of government activity and economic growth and whether "one size fits all". Their study investigates the role of government activity on economic growth, arguing that economic systems are important and consequently one size of government does not fit all countries. Taking a panel of 111 countries over the years from 1971 to 2010, they consider clusters of economic systems as predicted by an extended Varieties of Capitalism (VoC) approach. The empirical growth impact of government activity is positive but $\mathrm{u}$-shaped and depends on both the quality of institutions and the institutional setting. For the polar cases of liberal economies and Scandinavian coordinated market economies, the potential growth impact turns out to be quite similar and superior to other clusters of countries. However, the maximum growth effect is realized for above-average levels of government activity in the Scandinavian countries, while this would be detrimental to growth in liberal countries. Hence, high levels of government activity are consistent with growth but only in economic systems consistently rooted in a high level of government activity.

Two papers then deal more explicitly with the US economy and its links with the global one. First, Keshab Bhattarai, Jonathan Haughton, David Tuerck investigate the 
economic effects of the Fair Tax proposal by means of a Dynamic Computable General Equilibrium (CGE) Model of the US economy. The authors conclude that by replacing the current income tax with a national sales tax, the Fair Tax proposal would end the double taxation of saving inherent in the existing tax code and, by doing so, raise output, employment, investment and capital stock relative to the benchmark economy. While these positive effects would be felt almost immediately, the FairTax is very much an investment in the future. Its full benefits would be realized only after the economy achieved a new "steady state," some 20-25 years into implementation. Only at that point, will the effects on growth have been fully absorbed into the economy and the wellbeing of most households across most income groups improved. The policy choice, then, is between the status quo and a new policy that would inflict some short-run pain as the price of a permanently expanded economy.

A second paper by Kyriaki Begiazi, Dimitrios Asteriou and Keith Pilbeam delivers a multivariate analysis of United States and global Real Estate Investment Trusts. Using daily data for the period February 2006 to July 2013 they examine the return and volatility linkages between the two main United States REIT sub-sectors and global linkages between the Americas, Europe and the Asia Pacific regions using the BEKKGARCH and the DCC-GARCH models. The authors find that there is no evidence of any volatility spillovers between the US sub-sectors. By contrast, they find evidence of volatility spillovers between the Asia Pacific and the Americas, the Asia Pacific and Europe but no spillovers between the United States and Europe. Their results suggest that the REIT market is becoming increasingly globalized and that investors need to consider time varying volatility and correlations across different regions of the world when forming their optimal portfolio-allocations.

The special issue continues with two papers on the BRIC economies, namely India and Russia. In the first, Samaresh Bardhan, and Vivekananda Mukherjee look at bankspecific determinants of nonperforming assets of Indian banks. In their paper, they examine the role of bank-specific variables in explaining the dynamics of nonperforming assets (NPAs) of Indian banks in a panel data framework over the post liberalisation period, 1995-2011. The results have been derived after controlling for macroeconomic factors like real GDP, inflation, the exchange rate etc. Applying several variants of the Generalized Method of Moments (GMM) technique in dynamic models, the authors find that that there is significant time persistence of NPAs in Indian banking system. They also find that the larger banks are more prone to default than the smaller banks. Their results also find support for the 'bad management hypothesis' which predicts that past performance is negatively related to future NPAs where past performance is regarded as a proxy of managerial efficiency. Lagged capital adequacy ratio as an important prudential indicator also significantly reduces current NPAs of banks. The paper also draws some important policy implications about NPA management.

In the second, Irina Dubova models Russia's long-run real effective exchange rate. Due to its high dependence on natural resource exports and at the same time the absence of stable domestic policy, unexpected and/or excessive changes in the real exchange rate might negatively affect the Russian economy causing large welfare costs. Since the determinants as well the causal links to different fundamental determinants are not straightforward, she employs the Johansen cointegration framework to determine the factors that drive real exchanges rate in the long run. Compared to previous research on the Russian exchange rate, she expands the period of observations and 
constructs potential determinants as differences between domestic and foreign variables. This procedure might also be relevant for researchers analyzing other countries' exchange rates.

The European Economics and Finance Society (EEFS) thirteenth Annual Conference in Thessaloniki provided the opportunity for participants to gain new insights into some highly topical issues. We want to thank Paul Welfens for giving us a special issue of the International Economics and Economic Policy. We would also like to thank "Wissenschaftsförderung der Sparkassen-Finanzgruppe e.V." for generous funding and, above all, Joscha Beckmann, University of Duisburg-Essen, for his great contribution to the organization of this event and this special issue. We are also heavily indebted to the referees of the papers included in this special issue, their reports resulted in substantial and significant improvements that were appreciated by the authors of papers accepted in this special issue. 